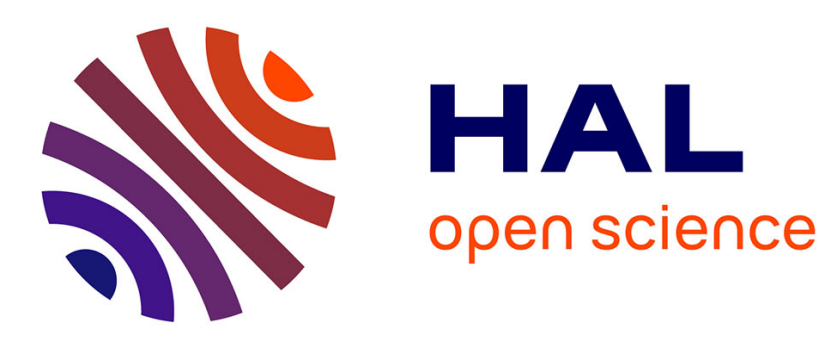

\title{
Artifact and Artifact Categorization: Comparing Humans and Capuchin Monkeys
}

Stefano Borgo, Noemi Spagnoletti, Laure Vieu, Elisabetta Visalberghi

\section{To cite this version:}

Stefano Borgo, Noemi Spagnoletti, Laure Vieu, Elisabetta Visalberghi. Artifact and Artifact Categorization: Comparing Humans and Capuchin Monkeys. Review of Philosophy and Psychology, 2013, vol. 4 ( $\mathrm{n}^{\circ} 3$ ), pp. 375-389. 10.1007/s13164-013-0144-5 . hal-01122801

\section{HAL Id: hal-01122801 https://hal.science/hal-01122801}

Submitted on 4 Mar 2015

HAL is a multi-disciplinary open access archive for the deposit and dissemination of scientific research documents, whether they are published or not. The documents may come from teaching and research institutions in France or abroad, or from public or private research centers.
L'archive ouverte pluridisciplinaire HAL, est destinée au dépôt et à la diffusion de documents scientifiques de niveau recherche, publiés ou non, émanant des établissements d'enseignement et de recherche français ou étrangers, des laboratoires publics ou privés. 


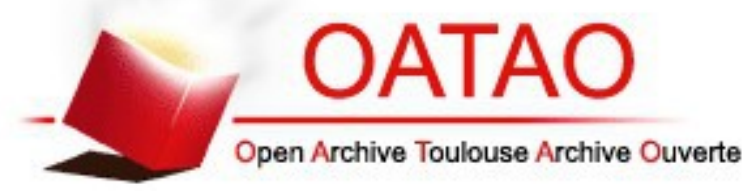

\section{Open Archive TOULOUSE Archive Ouverte (OATAO)}

OATAO is an open access repository that collects the work of Toulouse researchers and makes it freely available over the web where possible.

This is an author-deposited version published in : http://oatao.univ-toulouse.fr/ Eprints ID : 12613

To link to this article : DOI :10.1007/s13164-013-0144-5

URL : http://dx.doi.org/10.1007/s13164-013-0144-5

To cite this version : Borgo, Stefano and Spagnoletti, Noemi and Vieu, Laure and Visalberghi, Elisabetta Artifact and Artifact

Categorization: Comparing Humans and Capuchin Monkeys. (2013)

Review of Philosophy and Psychology, vol. 4 (n 3). pp. 375-389.

ISSN 1878-5158

Any correspondance concerning this service should be sent to the repository administrator: staff-oatao@,listes-diff.inp-toulouse.fr 


\title{
Artifact and Artifact Categorization: Comparing Humans and Capuchin Monkeys
}

\author{
Stefano Borgo • Noemi Spagnoletti • Laure Vieu • \\ Elisabetta Visalberghi
}

\begin{abstract}
We aim to show that far-related primates like humans and the capuchin monkeys show interesting correspondences in terms of artifact characterization and categorization. We investigate this issue by using a philosophically-inspired definition of physical artifact which, developed for human artifacts, turns out to be applicable for cross-species comparison. In this approach an artifact is created when an entity is intentionally selected and some capacities attributed to it (often characterizing a purpose). Behavioral studies suggest that this notion of artifact is not specific to the human kind. On the basis of the results of a series of field observations and experiments on wild capuchin monkeys that routinely use stone hammers and anvils, we show that the notions of intentional selection and attributed capacity appear to be at play in capuchins as well. The study also suggests that functional criteria and contextualization play a fundamental role in terms of artifact recognition and categorization in nonhuman primates.
\end{abstract}

\author{
S. Borgo $(\bowtie) \cdot$ L. Vieu \\ LOA-ISTC-CNR, Trento, Italy \\ e-mail: stefano.borgo@cnr.it \\ N. Spagnoletti \\ PSE-IP-University of São Paulo, São Paulo, Brazil \\ e-mail: noemi.spagnoletti@istc.cnr.it \\ N. Spagnoletti $\cdot$ E. Visalberghi \\ UCP-ISTC-CNR, Rome, Italy \\ E. Visalberghi \\ e-mail: elisabetta.visalberghi@istc.cnr.it \\ L. Vieu \\ IRIT-CNRS, Toulouse, France \\ e-mail: laure.vieu@irit.fr
}




\section{Introduction}

We aim to show that the human and the capuchin monkey (a far-related primate) are cognitively closer than generally accepted in categorizing natural and artificial entities. Assuming these commonalities are not accidental, the observation of capuchin monkey provides further evidence to identify which elements are most likely primary in both human and non-human primates' artifact categorization. We investigate this issue by using a philosophicallyinspired theory, developed for human artifacts, as a handle for a cross-species comparison. The theory is fairly simple yet complex enough to help in wellknown philosophical puzzles such as the ship of Theseus.

As far as it is known today, capuchin monkeys do not have a specific language for artifacts or artifactual entities, and seem to lack terms even for most natural entities. The comparison is thus based on behavioral evidence gained from capuchin monkeys in captivity and in the wild; this "behavioral" viewpoint is a limitation of our work that should be kept in mind.

\section{A Theory of Physical Artifacts}

It can be argued that ontologically physical artifacts, the artifacts most studied in the philosophical literature, see (Hilpinen 2011; Margolis and Laurence 2007), are not simply physical objects that have been physically modified or built by humans, as classically understood. Although the recognition of physical manipulation on an item gives us a strong indication of artifactness, physical manipulation is not essential: for a number of authors, the essence of artifacts lies in intentionality (Baker 2004; Dipert 1993; Thomasson 2007). We intentionally select objects in order to use them for a purpose, sometimes physically modifying them to suit our tasks. This gives a broader perspective on artifacts which includes "naturefacts" (Oswalt 1973), such as found art, and at the same time avoids counting as artifacts residues like sawdust and nonintentional animal constructs like wasp nests.

Borgo and Vieu (2009) discuss the case of a paperweight made of a pebble, an example of naturefact, and propose that the artifact (paperweight) is a creation obtained by some agent intentionally selecting an object (the pebble) and intentionally attributing to it some capacities (Cummins 1975), that is, dispositions or functionalities like holding paper without ruining it, being easily grasped by hand, being firm etc. The theory of physical artifacts proposed in (Borgo and Vieu 2009) presupposes a formal structure in which ontological categories like physical object, agent, quality and event, are characterized and related. The theory itself is formally instantiated relying on the foundational ontology DOLCE (Masolo et al. 2003) which, for simplicity, is also adopted in this paper. An attributed capacity is classified in the theory as an individual quality that characterizes the purpose or function of the artifact as determined by its creator(s). When the artifact does not perform according to the capacities attributed to it, it is said to be flawed or malfunctioning without contending the existence of the artifact itself. Of course, rational agents, on the basis of acquired expertise or knowledge of physics, usually ground their selection 
and capacity attribution on the observation of actual physical qualities that they assume to be relevant.

The assumption that the artifact (the paperweight in the previous example) is not identical to the physical object of which it is made (the pebble) is also crucial. This approach to physical artifacts contrasts the standard view that an artifact is a physical object with some extra (generally acquired) property, i.e., a function or a role (Vieu et al. 2008). In our approach the physical object and the physical artifact are co-located when both present but have different properties and in particular different lifetimes (the paperweight starts existing well after the pebble). In addition, the paperweight depends on - more specifically, is constituted by - the pebble but not vice versa. In fact, physical artifacts and physical objects obey different identity criteria as shown by the fact that artifacts can be repaired and undergo part substitution without losing their identity: they simply are constituted by different physical objects at different times. Such a substitution is ruled out by the view of artifacts as physical objects with extra properties since by altering the physical object one affects the identity of the artifact itself. Hence with our view, in the classical ship of Theseus puzzle (Lowe 1983), substituting a plank doesn't destroy the artifact, i.e., the ship, whose attributed capacities continue to persist, although it does destroy the original physical object that constituted it, i.e., the plank assembly. ${ }^{1}$ When the original planks are assembled again, depending on the identity criteria given to physical objects, one could argue that the original physical object comes back into existence. The artifact that is then created is though a different one with perhaps other attributed capacities.

Similarly, the intentional use of artifacts for purposes not considered at their creation time or the attribution of new capacities to existing artifacts give rise to new artifacts in this theory. This gives a simple answer to a deeply discussed identity issue, see (Houkes and Vermaas 2010), at the cost of multiplying (co-located) entities, a move not to the taste of all ontologists.

Artifacts can be divided in private, i.e., recognized by its creator only, and social (artifact proper à la Dipert 1993) when their intention-based properties take on a social dimension. More specifically, in (Borgo and Vieu 2009) social artifacts are artifacts whose status and type is recognized by members of a specific society. Following Borgo and Vieu, we use artifact type, or simply type, to indicate a description $^{2}$ of artifacts sharing some characteristics, i.e., an artifact kind for other authors. An artifact type specifies a number of attributed capacities and constrains the range of values these can take. ${ }^{3}$ In our society, most artifacts are social, like knifes and cars. Among the social artifacts, some are recognized because of their observable intrinsic properties: the type "knife" and its subtype "kitchen knife" are recognized in a given knife because of its particular shape and the material it is made of. Others, e.g., paperweights made out of pebbles, can be recognized as such only in their context of use, e.g., when placed on a pile of papers on a desk.

\footnotetext{
${ }^{1}$ The importance of constitution in this theory makes it closer to Baker's approach (Baker 2004). Differently from Baker's, artifacts here are not aggregates and the distinction between the artifact (ship) and the physical object (aggregate of planks) is preserved.

${ }^{2}$ In the DOLCE framework, types are non-physical entities of the ontological category of concepts, as introduced in (Masolo et al. 2004).

${ }^{3}$ See (Masolo et al. 2003) for further clarifications of the terminology regarding qualities among which we include attributed capacities.
} 
Physical artifacts can of course be distinguished in other ways, e.g. according to whether they are "naturefacts" or manufactured. In the latter case, they can be further divided according to the degree of manufacturing and the complexity of their constituting physical object. Naturefacts are necessarily simple, but manufactured artifacts are often constituted by assemblies. There are different views on the essential characteristics of technical artifacts (Borgo et al. 2011) and in this paper we take the view that technical artifacts are those manufactured according to a design, specifying a precise artifact type, a production method and a use plan (Houkes and Vermaas 2010).

Finally, tools form a class of physical artifacts whose attributed capacity is related to the purpose of physically acting on some other entity (unlike works of art, for instance). ${ }^{4}$ Usually, these are also social artifacts, like the knifes above.

Given this view on artifacts, the next section introduces the non-human primates that serve for our cross-species comparison of the ontological category of artifact.

\section{Capuchin Monkeys and Tool Use}

Capuchin monkeys (genus Cebus and Sapajus) are South American primates that separated from the human lineage about 35 million years ago, much earlier than chimpanzees (our closest relatives). Despite the phylogenetic distance the cognitive abilities of capuchins and chimpanzees show many similarities (Fragaszy et al. 2004). The abilities of capuchins appear cognitively more advanced than those of other New and Old World nonhuman primate species (Tomasello and Call 1997). Very recently, captive capuchins have been shown to be capable of: transferring relations from one situation or set of objects to a different one (Kennedy and Fragaszy 2008; Spinozzi et al. 2004), analogical reasoning (Truppa et al. 2001), applying relational structures in tool using tasks and being sensitive to the functional properties of the tools. In these tasks capuchins require more practice than chimpanzees but, eventually, they reach similar levels of performance.

A few primate species use tools in captivity (Shumaker et al. 2011). Among monkeys, the capuchins are the best tool users and their abilities are similar to those of chimpanzees. In nature only chimpanzees, among great apes, use tools habitually for diverse purposes and in many varied formats across their geographical distribution (Boesch et al. 2009). Tool use is observed much less often in wild orangutans (Pongo abelii), and in the other wild great apes (Western gorillas, Gorilla gorilla, and bonobos, Pan paniscus) though in captivity all the great ape species use tools spontaneously in flexible and diverse ways. Only a few species use tools in natural settings; Macaca fascicularis (Gumert et al. 2009) and capuchins excel in this respect. The reports on tool use by wild bearded capuchins (Sapajus libidinosus, formerly Cebus libidinosus) come from seasonally dry Cerrado and Caatinga habitats in the north and east of Brazil. It is worth to mention that given the very wide distribution of capuchin monkeys in Central and South America, tool use has been

\footnotetext{
${ }^{4}$ This characterization corresponds to the usual sense of tool in the lexicon as well as the use in ethology, but is quite different from Dipert's definition (Dipert 1993) as in particular they are not limited to manufactured artifacts.
} 
observed in very few species and only in a few locations. Therefore, it seems that individuals acquire this behaviour only in specific environmental circumstances and that its diffusion among group members is supported by social conditions (Fragaszy 2011). This suggests that the ability is acquired, requires intentionality and can be taken as cultural trait of some groups. At Fazenda Boa Vista, State of Piauí in Brazil capuchin monkeys crack open palm nuts and other encased foods with stone hammers and anvils. In other sites they use stones to access embedded food by percussion and by scraping, and sticks to probe for honey and to flush vertebrate prey (Mannu and Ottoni 2009).

Using a stone (or log) to crack open an encased food item placed on a solid surface (an "anvil") is considered the most complex form of tool use by nonhuman species routinely seen in nature because it involves producing two spatial relations in sequence between nut and anvil, and between pounding tool and nut (Matsuzawa 2001). Furthermore, transporting the food item and sometimes the percussor involves costs (time and energy, among others) and may present cognitive challenges, such as anticipating future needs, recalling elements that are out of sight, and planning the course of action. Transporting food resources and repetitive visits to specific places on the landscape to process foods are associated with early Homo and are thought to be important innovations of the Oldowan (Potts 1991).

\section{Comparative Analysis via the Artifact Theory}

Since 2004, we have carried out several observational studies and a series of field experiments on wild capuchins using hammer and anvil tools in Fazenda Boa Vista (Visalberghi et al. 2007). Here we report some of the collected evidence that the notion of artifact introduced in Section 2 applies to these monkeys. For a thorough description of the field experiments and their methodology, the interested reader can visit the website EthoCebus.net and check references within it.

In this section we argue that there is evidence that capuchins intentionally select objects on the basis of different qualities that they can perceive, e.g., by tapping and lifting them, and consistently use these objects, depending on the task to solve, according to the capacities they associate to them. This act of capacity association amounts to judge that an object can be used for a purpose, and thus corresponds to what we called capacity attribution in Section 2 . As we will see, these judgments are indeed fallible.

As already said, an adult capuchin usually exploits physical objects to crack nuts and other encased food. Spagnoletti et al. (2011) observed wild capuchins routinely using tools to crack open nuts of different resistance. Capuchins select the stone of the appropriate material and weight according to whether they have to crack open nuts (more resistant) or other encased foods (less resistant). Capuchin select stones heavy enough to crack the nut, even if the heavier stone is smaller than the lighter one (Visalberghi et al. 2009). Experimental work has also demonstrated that capuchins choose hard material (quartzite) instead of friable material (sandstone) when about to crack nuts.

Capuchins select stones never encountered before and paired in different assortments. This indicates that choice is intentional and not based on a sort of recognition 
of what has been successful before. Capuchins use generalized knowledge built upon their lifetime experience with percussive activities. We observed that juvenile capuchins need a lot of experience before acquiring the skills to select the appropriate physical qualities. They do select physical objects that are inadequate, e.g. sandstones that break when cracking hard nuts. This happens also, but rarely, with adult monkeys if there are no suitable stones nearby.

The attribution of capacities to selected objects are kept in capuchins' memory, suggesting artifact persistence. There is evidence that capuchins repeatedly use previously selected stone tools and anvil sites. An anvil has been observed in use 108 times over a period of 12 months. Further indirect evidence of persistence is based on anvils censused regularly and the presence of pits that require many tool strikes to be produced. When wild capuchins have a nut requiring a stone and an anvil for its exploitation, they actively search for anvil sites already used in the past. While doing so, capuchins increase their speed of locomotion also when the site is still out of view, suggesting that they know what to search for and where it is located.

Moreover, the same physical object is repeatedly used without thoroughly checking again its physical qualities. When capuchins are at a site previously used or seen to be used, exploratory behaviours meant to evaluate the affordance of the stone are absent or extremely rare suggesting that they have a notion of social artifact. Exploratory actions such as lifting/moving the hammer stone (to assess its mass) and tapping on it (to infer density/mass by means of the sound produced) were common towards home-made resin stones but not with stones of the material commonly encountered by capuchins in their home-range (Visalberghi et al. 2009).

These observations strongly suggest that capuchins do use tools or, more explicitly, physical artifacts to which they attribute the capacity to crack open nuts. The theory of artifacts presented above is suited to account for capuchin's behavior, since it is essentially based on attributing capacities, and not on manufacturing. A fundamental aspect of the theory, the assumption that there are two distinct entities, namely the artifact and the physical object constituting it, is particularly difficult to justify on the mere basis of capuchin's behavior. Nonetheless, we believe that one of our observations (video recorded by N. Spagnoletti, unpublished) provides some evidence for it. A juvenile capuchin, having selected a friable stone, keeps pounding on a nut while the stone repeatedly breaks up. He is thus holding at each strike a different stone but arguably the same artifact since he doesn't show doubts nor pauses after each breaking of the stone as one would expect. This suggests that a theory in which the identity criteria of artifacts differ from that of the physical objects constituting them is more adequate than one in which artifactualness is just a property of physical objects.

Capuchins have a high ability to select physical objects whose actual capacities very finely match the attributed capacity of the tools they need for a given purpose. They clearly distinguish two types of tools, hammers and anvils. These tools are not manufactured, although other populations do manufacture sticks out of leafed twigs to probe for honey and to flush vertebrate preys. It would even seem that the notion of social artifact may apply to capuchins as well. Preliminary evidence in this direction is that they wait "in queue" to use a hammer and anvil site (Spagnoletti et al. 2011). Once the waiting monkey has access to the anvil it preferably reuses the same pit used by the previous monkey, apparently relying on some notion of social recognition. 
Further studies are planned to clarify this issue and to circumscribe the extension of social recognition in capuchins.

So the behavioral evidence in the literature supports the claim that there is a strong similarity of artifact characterization in human and non-human primates. There are several open issues, however, like the capacity of capuchin monkeys to create complex artifacts. One interesting case study would be the assembly of a specific hammer with a specific anvil, thus constituting an instance of complex artifact, and in some sense a manufactured one. Indeed, in one case it has been observed (observation by Spagnoletti, see also Visalberghi et al. 2013) a capuchin bringing a hammer to an anvil from where it had disappeared time before, even though there were other anvils at a closer distance. Further evidence would be necessary to better interpret the importance of this observation in terms of artifact complexity in capuchins.

In the following section we discuss new experimental evidence that reinforces the claim that capuchin monkeys have a category of artifact similar to the one discussed in Section 2. In the rest of the paper, we use the term category in the ethological sense and use ontological category for the philosophical notion, while the term type is as introduced in Section 2. Our aim is to further justify the reading of the ethological categories we encountered in terms of the ontological category of artifact and artifact types.

\section{Tool Selection}

Here we address the independence of the capacity attribution by capuchin monkeys from other, arguably irrelevant, properties. More specifically, we ask whether in the context of cracking open nuts there are features, in addition to functional ones such as friability and weight, affecting the tool selection and, if so, whether these can be shown to provide advantages without altering the tool's capacity to achieve the goal. In the experiment described in detail below, capuchins choose between hammer stones (all suitable to crack open nuts) that differ in terms of (a) easiness to be handled (relevant feature) and (b) color (irrelevant feature). In each trial the choice was between a stone with a smooth surface (smooth stone), and a stone with protuberances on its surface (bumpy stone). The two stones differed in colour, with the smooth stone white and the bumpy stone black, or vice versa. We hypothesized that protuberances made the bumpy stone less comfortable for transportation and use than the smooth one. Color was considered an irrelevant feature. In the first condition, each subject received ten trials in which each of the relevant feature was always paired with an irrelevant feature (e.g., the smooth stone was black, whereas the bumpy stone was white). Then, in the second condition, the pairing was switched (e.g., the smooth stone was white, whereas the bumpy stone was black). This procedure allowed us to sort out the feature(s) taken into account by capuchins.

\section{Materials and Methods}

Our field site was located at Fazenda Boa Vista in the southern Parnaíba Basin $\left(9^{\circ} 39^{\prime}\right.$ $\mathrm{S}, 45^{\circ} 25^{\prime} \mathrm{W}$ ) in Piauí, Brazil. It is a flat open woodland (altitude $420 \mathrm{~m}$ asl) 
punctuated by sandstone ridges, pinnacles and mesas rising steeply to $20-100 \mathrm{~m}$ above it.

Subjects were four adult males, one adult female and one juvenile male. Experiments were carried out in an area where capuchins routinely use tools to crack open palm nuts where several anvils are present. For the purpose of the study, we removed all stone hammers.

We used a set of 8 artificial stones all weighing about $600 \mathrm{~g}$; we had two black bumpy stones, two white bumpy stones, two white smooth stones and two black smooth stones (for an example see Fig. 1). Artificial stones were made by filling silicon plasters of different size and shapes with unsaturated liquid polyester resin (Silica synthetic Amorphous Colloidal Silicon Dioxide, aereosil), and Organic Peroxides for curing (Butanox M 50). White or black pigments were added to the resin. To obtain the desired weight, the stone interior was filled with resin containing either calcium carbonate or lead beads.

In each trial, the subject had to choose between two stones to crack open a palm nut. Stones were always positioned in the same location (hereafter, choice location), at $60 \mathrm{~cm}$ from one another. The choice location was halfway between a log (wooden anvil, $0.24 \mathrm{~m}$-high) and a sandstone anvil (low anvil, at ground level), at a distance of $4 \mathrm{~m}$ from both of them. Other sandstone anvils were also present in the area.

Each subject was tested in two conditions of 10 trials each. In one condition the bumpy stone was black and the smooth one was white, whereas in the other condition the bumpy stone was white and the smooth was black. The order in which the two conditions were presented was balanced across subjects. Each trial started when one of the experimenters provided a nut to the subject; this occurred either by positioning the nut on the wooden anvil (at a distance of $4 \mathrm{~m}$ from the choice location), or by throwing the nut near the subject (at a distance of $4 \mathrm{~m}$, or more, from the choice location). This procedure guaranteed that the subject was equidistant from the experimental stones, or approximately so.

Since capuchins like food variety, we presented two species of palm nuts: the tucum (Astrocaryum spp.) and the catule (Attalea spp.). The peak-force-at-failure of these nuts, routinely cracked open with tools by capuchins in FBV, is not significantly different (Visalberghi et al. 2007).

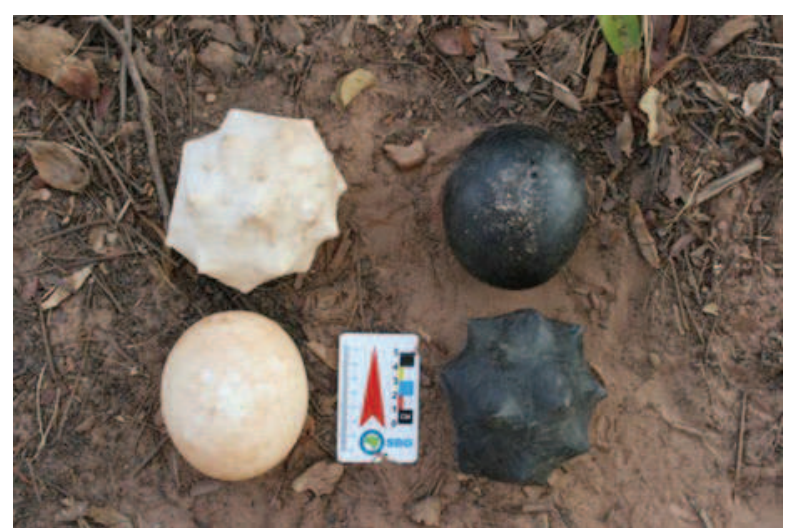

Fig. 1 Exemplars of the smooth stones (lower left and upper right) and the bumpy stones (upper left and lower right) presented during the experiment, in white and black (Photo by E. Visalberghi) 
Two experimenters scored the data by paper and pencil from a distance of $5.0 \mathrm{~m}$ from the choice location, while a third one set the tool pair as required by the trial and provided the subject with the nut. The experiment was videotaped and scored for reliability by a naïve observer who was blind to condition. We scored the first stone touched, transported, and used to strike the nut, anvil used and success. Reliability scored on $25 \%$ of the trials was $100 \%$.

\section{Results and Discussion}

Through the experiment, all subjects almost always contacted and manipulated first the smooth stone regardless of its color. In 59 out of 60 trials of the first condition, they transported and used the smooth stone and, in the second condition, always kept using the smooth stone despite its change in color (see Table 1 and Fig. 2). This demonstrates that capuchins preferred the smooth stone also when the association color-surface was switched. Capuchins were successful in 113 trials out of 120 (94\%). In the only trial in which a bumpy stone was used the subject (Jatobà) succeeded. Furthermore, in a few cases the female Chuchu and Chicao and Tucum (one adult male and one juvenile male) gave up after many strikes, possibly because the nut was too resistant to be opened with a stone of $0.6 \mathrm{~kg}$.

The wooden anvil was the most chosen by all subjects being used in 99 out of 120 trials (see Fig. 2). In 19 trials other anvils present in the area were used; in two trials 2 and 3 different anvils were used by transporting the stone from one to the other.

Table 1 Performance of each subject in the B-smooth condition (in which the smooth stone is black) and in the W-smooth condition (in which the smooth stone is white). $F$ female, $M$ male; Ad Adult, $J$ Juvenile; contact number of trials in which the stone contacted first was the smooth one; manipulation number of trials in which the stone manipulated first was the smooth one: transport number of trials in which the stone transported to the anvil was the smooth one; use number of trials in which the stone used to crack the nut was the smooth one; success number of trials in which the subject succeeded; \# anvils number of different anvils used during each condition

\begin{tabular}{|c|c|c|c|c|c|c|c|c|c|}
\hline Subject & Sex & Age & Condition & Contact & Manipulation & Transport & Use & Success & $\#$ anvils \\
\hline \multirow[t]{2}{*}{ Chuchu } & \multirow[t]{2}{*}{$\mathrm{F}$} & \multirow[t]{2}{*}{$\mathrm{Ad}$} & B-smooth & 10 & 10 & 10 & 10 & 7 & 3 \\
\hline & & & W-smooth & 10 & 10 & 10 & 10 & 10 & 3 \\
\hline \multirow[t]{2}{*}{ Chicao } & \multirow[t]{2}{*}{ M } & \multirow[t]{2}{*}{ Ad } & W-smooth & 10 & 10 & 10 & 10 & 10 & 1 \\
\hline & & & B-smooth & 10 & 10 & 10 & 10 & 7 & 1 \\
\hline \multirow[t]{2}{*}{ Mansinho } & \multirow[t]{2}{*}{ M } & \multirow[t]{2}{*}{ Ad } & W-smooth & 10 & 10 & 10 & 10 & 10 & 2 \\
\hline & & & B-smooth & 10 & 10 & 10 & 10 & 10 & 5 \\
\hline \multirow[t]{2}{*}{ Dengoso } & \multirow[t]{2}{*}{ M } & \multirow[t]{2}{*}{$\mathrm{Ad}$} & B-smooth & 8 & 10 & 10 & 10 & 10 & 1 \\
\hline & & & W-smooth & 9 & 10 & 10 & 10 & 10 & 2 \\
\hline \multirow[t]{2}{*}{ Jatobà } & \multirow[t]{2}{*}{ M } & \multirow[t]{2}{*}{ Ad } & B-smooth & 10 & 9 & 9 & 10 & 10 & 2 \\
\hline & & & W-smooth & 8 & 10 & 10 & 10 & 10 & 1 \\
\hline \multirow[t]{2}{*}{ Tucum } & \multirow[t]{2}{*}{ M } & \multirow[t]{2}{*}{$\mathrm{J}$} & W-smooth & 10 & 10 & 10 & 10 & 9 & 1 \\
\hline & & & B-smooth & 10 & 10 & 10 & 10 & 10 & 2 \\
\hline
\end{tabular}



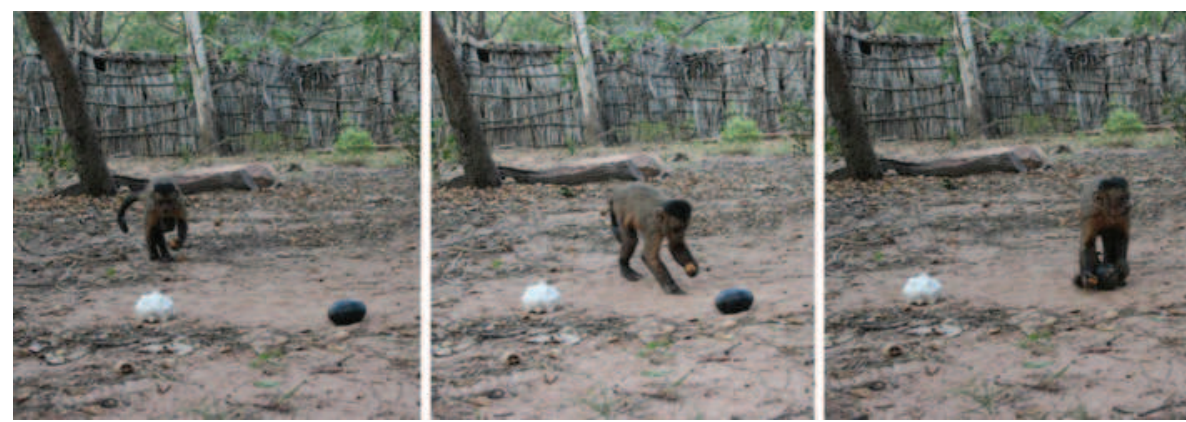

Fig. 2 (Left) The adult male (Dengoso) having received the nut at the wooden anvil (in the far back) moves towards the choice location holding the nut in his left hand; (centre) he approaches the smooth black stone and (right) starts to lift it. The bumpy white stone on the left is not even touched (Photo by E. Visalberghi)

As noted above the bumpy stone was almost never used. Therefore, to assess its effectiveness we provided some extra trials in which subjects had a choice between two bumpy stones. Results showed that capuchins reached success with a number of strikes similar to those obtained with smooth stones (Fig. 3). This suggests that bumpy stone can be used effectively when needed. In this respect, it is worthwhile mentioning that we repeatedly observed capuchins using siltstones that were bumpy and sharp, when cracking nuts in the forest.

Overall, the results of this experiment demonstrate that capuchins' choice can take into account also a relevant non-functional feature, such as easiness to handle the

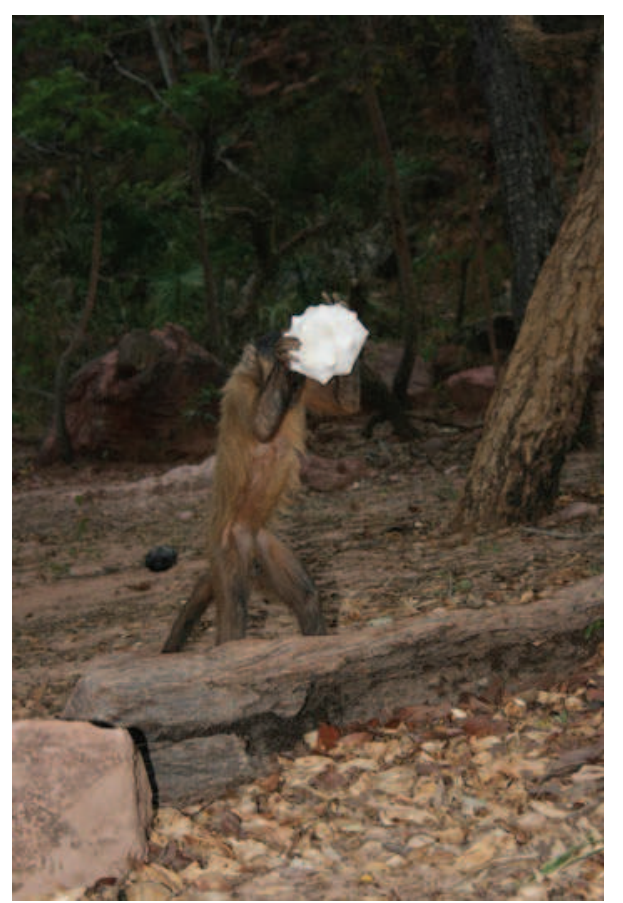

Fig. 3 The adult male Jatoba is using a bumpy stone to crack a nut on the wooden anvil (Photo by E. Visalberghi) 
stone while ignoring an irrelevant non-functional feature like color. Wild capuchins' recognition of affordances probably relies on their lifelong experience with a wide variety of stones, some of which are more comfortable on their hands when transported and used than others. This result adds evidence to the claim that selection and capacity attribution in capuchin monkeys are comparable to those of humans.

\section{Artefact Subcategories as Types}

As we have seen, capuchins' selection process of stone tools and anvils is quite sophisticated as it examines several properties. From long term observations, it has been definitely established that, when necessary, capuchins select stones of higher weight for nuts of high resistance than for nuts of low resistance; moreover, they choose stones of friable material and very light only for encased food items that are less resistant than low resistant nuts (Spagnoletti et al. 2011). These findings and further experiments by Visalberghi et al. (2009) provide a clear demonstration that capuchins have a rich structure of (ethological) categories into which they categorize artifacts. These include at least the categories of anvil and (stone) hammer; and the latter is further refined into subcategories distinguished by functional and non-functional features (among which material, weight and shape), by purpose (the opening of a hard nut with minimal effort and without ruining the content vs the opening of softer nuts or other food items) and even by context (the distance of the stone from the chosen anvil). We do not have enough evidence to discuss subcategories within the anvil category although it is known that, even in this case, capuchins can make fine distinctions about the anvils' material (stone or wood) and features of the pits in them (Liu et al. 2011). The rest of the paper will focus on the structure of the capuchins' category of hammers which is the most studied and understood capuchins' category as of today.

As we have seen, the refinement of the stone hammer category in capuchins is supported by a series of independent observations. These all confirm that capuchins' stone selection takes into consideration several features of the tool, like material and weight, as well as features of the items to be cracked open with the tool, like shell resistance. The selection process optimizes the distinguishing features of the object to use and the relevant features of the shell to crack open including also evaluations of the effort to bring the objects to the anvil. The concomitant examination of a large number of parameters during the selection process is further corroborated by a recent field experiment in which Massaro and Visalberghi (unpublished results) tested five capuchins with a low resistant nut, or with a high resistant nut. In each trial the subject could choose between a $0.6 \mathrm{~kg}$ hammer stone already positioned on the anvil and a $2 \mathrm{~kg}$ hammer stone positioned at distance of $4 \mathrm{~m}$ from the anvil $(2 \mathrm{~m}$ for one subject). In short, whereas the use of the light stone was readily available, the use of the heavy stone had a cost in terms of transport to the anvil. Results indicate that all subjects chose the light stone in the trials with low resistance nuts, whereas they chose and transported the heavy stone in trials with the high resistant nuts. 
In conclusion, capuchins categorize stone tools on the basis of several features. Some of them are hierarchically more important (e.g., weight and material) since they strongly affect tool functionality, whereas others (such as smoothness) are less important because only mildly affecting functionality. They also take into account the resistance of the nut during the process of tool selection and other contextual elements like the distance of the preferred hammer from the anvil, which affects the total costs of tool use. If we separate the contextual elements from the characterizing features, we can conclude that the capuchins' (stone) hammer category is structured into at least three subcategories: hammers for high resistant nuts, hammers for low resistant nuts and hammers for food items encased in even less resistant shells. The analysis of these subcategories and their consistent recognition across capuchins in the studied groups suggest that these subcategories correspond to types as introduced in Section 2. This correspondence is quite natural: the capuchins' subcategories are determined just by looking at some properties of the tools (like hardness and weight) which must have values within some optimal range. Remaining features of the physical object under consideration (like color and smoothness) are irrelevant to its categorization although may determine preferences for usage. This shows that the subcategory is consistently associated to a set of features and that attribution of capacities depend on their values only.

Within the three subcategories, capuchins make consistent choices with regard to other features like smoothness vs bumpiness. These features play however a secondary role since they affect selection only within one of the above subcategory. Clearly, the description of the three subcategories is based on a particular classification of food items. This result could be a byproduct of the investigation based on behavioral studies only. While acknowledging this limitation, one can suggest that the development of capuchins' categorical structure might be strongly influenced by categorization of the natural objects of interest, i.e., the food items. An interesting question is whether these artifact subcategories do in fact reflect the environmental features and the individuals living experiences, or are somehow independent from these. Provided we accept that artifact categorizations in primates share a common nature, an answer to this issue would have important consequences on the debate about the nature of artifact categorization in humans. In the case of capuchin monkeys, findings from other field sites clearly suggest that these specific categories are far from being fixed across capuchin populations. In an environment in which the resistance of the food items processed with tools are less extreme than in our site, Ferreira et al. (2009) found that capuchins still use stones of different weight to process food items of different resistance, see also (Falótico 2011). Therefore, if artifact categorization is acknowleged in all studied capuchin groups that use tools, the category structures they form are sensitive to what the individual has experienced in its environment given the resources available.

\section{Conclusion}

The results reported here indicate that a philosophically-motivated definition of artifact developed for humans applies equally to capuchin artifacts, and so it fails to characterize human artifacts, apart from adding the simple restriction 
that the creator must be human. While we recognize that a deep understanding of capuchin categorization is still not at our reach, what we know today suggests that human characterization needs to be strengthened with new conditions or that, as we suspect, we should accept that the notion of artifact is not specific to the human kind.

When specific sub-classes of artifacts are concerned, the matter becomes less clear. We mentioned above that the status of complex artifacts and social artifacts is unclear in capuchins; studies specifically focused on these notions are still missing. For social artifacts, this study requires to assess capuchins' intentionality. We generally attribute intentionality to others in our species relying on our rich communication and behavioral system as well as on similarity and co-evolution factors. The situation is different when considering capuchins, and capuchin behavioral studies regarding the attribution of intentionality to their kin concerning artifacts still need to be done. Nevertheless, ongoing experiments are expected to shed some light on relevant social aspects: in particular we are currently studying how the social context influences juveniles' learning processes in tool selection and tool handling.

One could think that no capuchin artifact instantiates the notion of technical artifact in the sense used here, i.e., artifacts manufactured according to a design specifying a precise artifact type, a production method and a use plan. Wild capuchins have not been observed to manufacture hammers and anvils or to produce flakes for a specific goal but it seems they also have no actual reason to produce them. Indeed, captive capuchins can be trained to do so (Westergaard and Suomi 1994). Also, wild capuchins do manufacture other tools, stripping leaves off twigs and, as described above, they certainly handle artifact types and have clear use plans. So the hypothesis that capuchin's do not have a notion of technical artifact is not really confirmed, unless we take designs to be informational entities that can be explicitly and intentionally communicated to others. This suggestion constitutes a restriction of the notion of design and brings in another aspect we have ignored in this paper: information transmission. Capuchins have a communication system but we ignore if they have terms to refer to specific individual objects, as the stone tools. Currently studies are in progress. Furthermore, capuchins do not carry actions aimed at teaching others. Similarly, capuchins do not even hand food at offsprings. So enriched, the notion of design and the derived notion of technical artifact would likely not be applicable to capuchins and would, perhaps, be proper to human primates. And it would support the fact that technical artifacts seem to evolve, new designs superseding earlier ones, much rapidly in humans than in other primates.

To conclude, our studies show that human and capuchins are cognitively closer than usually accepted and give hints on how to enrich the adopted formal theory of artifacts to account for more specifically human notions.

Acknowledgments This interdisciplinary work has arisen within the Institute of Cognitive Sciences and Technologies of the Italian CNR, across the Laboratory for Applied Ontology and the Unit of Cognitive Primatology \& Primate Center.

Permission to work in Brazil was granted by IBAMA and CNPq to N.S. and E.V. Thanks to the Oliveira family for permission to work at Boa Vista and logistical support. Thanks to Elsa Addessi to have collected the data of the Experiment here reported with E.V. and N.S. 


\section{References}

Baker, L.R. 2004. The ontology of artifacts. Philosophical Explorations 7(2): 99-111.

Boesch, C., J. Head, and M. Robbins. 2009. Complex tool sets for honey extraction among chimpanzees in Loango National Park, Gabon. Journal of Human Evolution 56: 560-569.

Borgo, S. and Vieu, L. 2009. Artefacts in formal ontology. In Anthonie Meijers, editor, Handbook of philosophy of technology and engineering sciences, Elsevier, 273-308.

Borgo, S., Franssen, M., Garbacz, P., Kitamura, Y., Mizoguchi, R. and Vermaas, P. 2011. Technical artifact: An integrated perspective. In Vermaas, P. and Dignum, V. eds, Formal Ontologies Meet Industry - Proceedings of FOMI 2011, IOS Press, 3-15.

Cummins, R. 1975. Functional analysis. Journal of Philosophy 72: 741-765.

Dipert, R. 1993. Artifacts, art works, and agency. Philadelphia: Temple University Press.

Falótico, T. 2011. Uso de ferramentas por macacos-prego (Sapajus libidinosus) do Parque Nacional Serra da Capivara - PI. Tese de Doutorado em Psicologia Experimental. Instituto de Psicologia. Universidade de São Paulo. São Paulo-SP. 172 p.

Ferreira, R., L. Jerusalinsky, T. Silva, M. Fialho, A. Fernandes, A. Roque, and M.F. Arruda. 2009. On the occurrence of Cebus flavius (Schreber 1774) in the Caatinga, and the use of semiarid environments by Cebus species in the Brazilian state of Rio Grande do Norte. Primates 50: 357-362.

Fragaszy, D. 2011. Community resources for learning: how capuchin monkeys construct technical traditions. Biological Theory 6: 231-240.

Fragaszy, D., E. Visalberghi, and L. Fedigan. 2004. The complete capuchin: The biology of the genus Cebus. Cambridge: Cambridge University Press.

Gumert, M., M. Kluck, and M. Malaivijitnond. 2009. The physical characteristics and usage patterns of stone axe and pounding hammers used by long-tailed macaques in the Andaman Sea region of Thailand. American Journal of Primatology 71: 594-608.

Hilpinen, R. 2011. Artifact. In Edward N. Zalta (ed), The Stanford encyclopedia of philosophy (Winter 2011 Edition), URL $=<$ http://plato.stanford.edu/archives/win2011/entries/artifact/ $>$.

Houkes, W. and Vermaas, P. 2010. Technical functions. On the use and design of artefacts. Springer.

Kennedy, E.H., and D. Fragaszy. 2008. Analogical reasoning in a capuchin monkey (Cebus apella). Journal of Comparative Psychology 122: 167-175.

Liu, Q., D. Fragaszy, B. Wright, K. Wright, P. Izar, and E. Visalberghi. 2011. Wild bearded capuchin monkeys (Cebus libidinosus) place nuts in anvils selectively. Animal Behaviour 81(1): 297-305.

Lowe, E.J. 1983. On the identity of artifacts. The Journal of Philosophy 80(4): 220-232.

Mannu, M., and E.B. Ottoni. 2009. The enhanced tool-kit of two groups of wild bearded capuchin monkeys in the Caatinga: tool making, associative use, and secondary tools. American Journal of Primatology 71: $242-251$.

Margolis, E. and Laurence, S. (eds) 2007. Creations of the mind: Theories of artifacts and their representation. Oxford University Press.

Masolo, C., Borgo, S., Gangemi, A., Guarino, N. and Oltramari, A. 2003. Wonderweb deliverable 18 Technical report. CNR, 2003.

Masolo, C., L. Vieu, E. Bottazzi, C. Catenacci, R. Ferrario, A. Gangemi, and N. Guarino. 2004. Social roles and their descriptions. In Proceedings of the 9th Int. Conf. on Principles of Knowledge Representation and Reasoning (KR 2004), ed. D. Dubois and C. Welty, 267-277. Menlo Park: AAAI Press.

Matsuzawa, T. 2001. Primate foundations of human intelligence: A view of tool use in nonhuman primates and fossil hominids. Tokyo: Springer.

Oswalt, W.H. 1973. Habitat and technology: The evolution of hunting. New York: Holt, Rinehart, and Winston, Inc.

Potts, R. 1991. Why the Oldowan? Plio-Pleistocene tool making and the transport of resources. Journal of Anthropological Research 47: 153-176.

Shumaker, R., K. Walkup, and B. Beck. 2011. Animal tool behavior: The use and manufacture of tools by animals. Baltimore: John Hopkins University Press.

Spagnoletti, N., E. Visalberghi, E. Ottoni, P. Izar, and D. Fragaszy. 2011. Stone tool use by adult wild bearded capuchin monkeys (Cebus libidinosus). Journal of Human Evolution 61: 97-107.

Spinozzi, G., G. Lubrano, and V. Truppa. 2004. Categorization of above and below spatial relations by tufted capuchin monkeys (Cebus apella). Journal of Comparative Psychology 118(4): 403-412.

Thomasson, A. 2007. Artifacts and human concepts. In Creations of the mind: Theories of artifacts and their representation, ed. E. Margolis and S. Laurence, 52-73. Oxford: Oxford University Press.

Tomasello, M., and J. Call. 1997. Primate cognition. Oxford: Oxford University Press. 
Truppa, V., E. Piano Mortari, D. Garofoli, S. Privitera, and E. Visalberghi. 2001. Same/different concept learning by capuchin monkeys in matching-to-sample tasks. PLoS One 6(8): e23809.

Vieu, L., S. Borgo, and C. Masolo. 2008. Artefacts and roles: Modeling strategies in a multiplicative ontology. In Proceedings of the 5th International Conference on Formal Ontology in Information Systems (FOIS 2008), ed. C. Eschenbach and M. Gruninger, 121-134. Amsterdam: Ios Press.

Visalberghi, E., D. Fragaszy, E. Ottoni, P. Izar, M. Gomes de Oliveira, and F. Andrade. 2007. Characteristics of hammer stones and anvils used by wild bearded capuchin monkeys (Cebus libidinosus) to crack open palm nuts. American Journal of Physical Anthropology 132: 426-444.

Visalberghi, E., E. Addessi, N. Spagnoletti, V. Truppa, E. Ottoni, P. Izar, and D. Fragaszy. 2009. Selection of effective stone tools by wild capuchin monkeys. Current Biology 19: 213-217.

Visalberghi E., Haslam M., Spagnoletti N., Fragaszy D. (2013) Use of stone hammer tools and anvils by bearded capuchin monkeys over time and space: dynamic construction of an archeological record of tool use. Journal of Archeological Science. http://dx.doi.org/10.1016/j.jas.2013.03.021.

Westergaard, G.C., and S.J. Suomi. 1994. A simple stone-tool technology in monkeys. Journal of Human Evolution 27: 399-404. 